\title{
AS FORMAS E AS REFORMAS DA IDENTIDADE XAVANTE: UMA ABORDAGEM METODO- LÓGICA
}

Maria Cristina Rezende de Campos ${ }^{1}$

\section{Resumo}

Este estudo busca uma compreensão sobre as formas artísticas e culturais que identificam a sociedade Xavante e suas transformações acarretadas pelo contato com o homem "branco". É um estudo comparativo sobre os aspectos observados pelos antropólogos Maybury-Lewis e Regina Müller e a pesquisa de campo que estou desenvolvendo nas Aldeias Abelhinha e Sangradouro, no Estado Mato Grosso. Evidencio a forma de organização dualista em que a Sociedade Xavante trabalha para criar uma síntese harmônica, a partir de idéias, categorias e instituições antitéticas que constituem seu modo de vida. E, também, as marcas identitárias impregnadas de códigos comunicantes, que têm na ornamentação corporal expressão simbólica.

Palavras-chave: Ornamentação corporal, Cultura Xavante, Formas artísticas.

\begin{abstract}
This study searches a comprehension of artistic and cultural forms that identify the Xavante society and its transformations occurred from the contact with the "white" man. It's a comparative study of aspects observed by the anthropologists Maybury-Lewis and Regina Müller and a field research that I am developing in Abelinha e Sangradouro village, in Mato Grosso state. I evidence the dualistic organization form that the society Xavante works to create a harmonic synthesis from ideas, antithetic categories and institutions, that built its way of live. And also the identity marks impregnated with communicative codes, which have in body ornamentation its symbolic expression.
\end{abstract}

Key-words: Body ornamentation, Xavante Culture, Artistc forms.

O caráter dinâmico da vida cultural exige a formulação de novos significados ou a recriação de símbolos tradicionais, seja no sentido da reafirmação da ordem e das concepções vigentes, seja no sentido de sua reformulação. Lux Vidal (1992) pontua que cada cultura em particular mantém-se nesta tensão provocada pela articulação entre tradição e inovação e considera que recriar a tradição, introduzindo novos sentidos e novos símbolos são alguns dos processos que dão à cultura sua vitalidade e sua força.

A Nação Indígena Xavante vive hoje entre os estados de Mato Grosso e Goiás, Centro-Oeste do Brasil, numa região de cerrado. São cerca de dez mil pessoas, vivendo em 55 aldeias, em sete reservas diferentes: Rio das Mortes, Couto Magalhães, Marechal Rondon, Areões, São Marcos, Sangradouro e Parabuburi. A língua que falam está classificada no tronco Jê.

Aproximadamente sessenta anos após o contato, o povo Xavante vive ainda preservando sua cultura e o que resta do complexo ecossistema do cerrado nessa região do país, que foi devastada pela monocultura e pecuária. No entanto, é clara a interferência direta e indireta do "branco" na cultura Xavante, o que causa sérios problemas para a sobrevivência das aldeias.

1 Universidade do Estado do Rio de Janeiro, RJ. 
Contatados no final da década de trinta, mostravam-se constantemente hostis aos missionários, aventureiros e agentes do governo brasileiro. De acordo com dados revelados por Maybury-Lewis (1984), a força aérea brasileira fez vôos de reconhecimento à sua procura e trouxe de lá fotografias de aldeias em forma de ferradura e de grandes homens nus que atiravam flechas nos aviões.

Hoje, as casas de alvenaria da Aldeia Sangradouro, construídas com materiais industrializados, não são dispostas no semicírculo tradicional, mas em filas formando ruas ao lado da Missão Salesiana. No entanto, a comunidade da Aldeia Abelhinha, composta por oito famílias, em seu projeto de resgate aos costumes tradicionais da sociedade Xavante, mantém suas casas dispostas em forma de ferradura, porém, com modificações em relação à matéria prima utilizada em sua construção. Por tradição, as casas são construídas como metade de um globo, fincado na terra de cabeça para baixo, feitas com madeira do cerrado e cobertas de palha de indaiá.

Os estudos sobre os povos Jê apontam como sua característica principal a convivência de um sistema tecnológico "simples" - adaptado às condições ambientais - com um sistema sociocultural extremamente complexo. Tais sistemas organizam-se através de um dualismo estrutural que se manifesta por uma multiplicidade de metades nos planos sociais.

No caso dos Xavantes, Aracy L. da Silva (1986) afirma que os indígenas são regidos por uma complexa organização social de tipo dualista, ou seja, trata-se de uma sociedade em que a vida e o pensamento de seus membros estão constantemente permeados por um princípio diádico, que organiza sua percepção do mundo, da natureza, da sociedade e do próprio cosmos como estando permanentemente divididos em metades opostas e complementares. Trata-se, na verdade, da chave da elaboração cultural dos Xavantes, construída e reconstruída através dos tempos e das variadas experiências históricas, mas sempre mantidas como ser, pensar e viver.

Este princípio diádico encontra expressão nos complexos rituais, grupos cerimoniais masculinos, grupos de nominação, classes de idade, competições esportivas, etc. A base deste ordenamento está centrada numa divisão em duas metades, que se complementam - os clãs Ôwawẽ (Rio Grande) e o Po'reạa'õno (Girino).

De acordo com o modelo diádico construído Maybury-Lewis (1984), a sociedade Xavante poderia ser apresentada como um conjunto de instituições moldadas em uma série de antíteses por analogia. A noção de "sociedade dialética" aponta a posição central dessa teoria social que postula que a harmonia vislumbrada como causa final só pode ser alcançada pela complementaridade dos contrários.

Conforme Müller (1976), os Xavantes têm como código simbólico a ornamentação corporal, que se expressa pela forma, cor e adornos específicos relacionados à classificação do indivíduo segundo a linhagem, o grupo social, a classe e a categoria de idade, bem como a função ritual que exerce em determinado cerimonial. $\mathrm{O}$ indivíduo decora seu corpo segundo o evento e o grupo social a que pertence. A ornamentação completa do indivíduo é que o diferencia ou identifica em relação aos demais. A pintura do corpo e os adornos móveis constituem uma linguagem visual que funcionam como marca de identificação étnica, refletindo a maneira pela qual o indivíduo se socializa como membro de uma comunidade.

De acordo com Berta Ribeiro (1989), essa prática de embelezamento que reveste o corpo tem para seus usuários valores e significados que o observador só chega a perceber quando se entranha profundamente na cultura dessa sociedade. 
A grosso modo, isso sugere não existir o que chamamos de natureza independente da cultura. Para obter informação adicional necessária no sentido de agir, fomos forçados a depender cada vez mais de fontes culturais - o fundo acumulado de símbolos significantes, como diz Geertz (1989). Para o autor, o conceito de cultura é essencialmente semiótico. Assume a cultura não como uma ciência experimental em busca de leis, mas como uma ciência interpretativa, à procura do significado.

Assim, para traduzir as marcas que identificam a sociedade Xavante, é necessário se enveredar pelas entranhas que formam o "corpus" deste grupo.

Nos punhos e tornozelos, os Xavantes usam cordões de fibra vegetal. Estes enfeites - danipsi - cordãozinho torcido de fios de palha de buriti ou embira, amarrado em várias voltas, com um nó central, conforme Müller (1976), parecem marcar as áreas cobertas pela pintura corporal, além de cumprirem também, uma função mágica.

Usam no pescoço, em ocasiões de cerimônia, a gravata (colar tsõrebæu, em xavante); feita de fios de algodão torcido. Em cada extremidade, o algodão é desfiado formando um tufo; o nó é dado na frente; atrás são presas penas de gavião, de rabo de papagaio, do pássaro chamado sirudu, do beija-flor vermelho, do mutum ou arara-azul, de acordo com a função ritual ou mágica que seu usuário tem o dever e o privilégio de exercer.

A identidade masculina Xavante está intimamente ligada aos brincos que aumentam de espessura de acordo com a idade. Para eles, quanto mais velho o homem, maior responsabilidade assume sobre a origem do seu povo. E para compreendê-la é necessário considerar o seu precedente mítico que estabelece narrativa expressa em seu corpo.

A furação de orelha é uma das fases do ritual Danhõno que prepara os adolescentes para a vida de guerreiro, incentivando a coragem e a independência. Quando o jovem fura a orelha, deixa de ser considerado um wapté (adolescente) e se torna um ritei'wa (rapaz). Então ele sai da casa dos adolescentes e pode se reintegrar na comunidade. "Só ao receberem batoques auriculares, porém, é que passam à condição plena de homens, ou seja, só a partir desse momento é que estão socialmente autorizados a exercer sua potência sexual". (MAYBURY-LEWIS, 1984: 314). Esse ritual constitui momentos importantes que marcam a socialização de um indivíduo ou a passagem de um grupo de uma situação para outra. Eles marcam momentos constituintes da identidade dos indivíduos nas diferentes fases da vida.

Assim como em outras tribos indígenas, os homens Xavantes usavam o estojo peniano. Trata-se de um protetor sexual masculino, feito de folíolo de broto de palmeira, que consiste em uma dobradura afunilada, com orifício na ponta, para imprensar o prepúcio e ocultar a glande. O estojo só cobre, portanto, a extremidade de seu órgão genital. Além do estojo, eles não usavam nenhum outro tipo de vestimenta e andavam completamente nus. De acordo com Maybury-Lewis (1984) consideravam extrema falta de decoro um homem ser visto sem essa proteção. Porém, em virtude do contato com a civilização, os Xavantes, atualmente, usam vestimentas iguais aos "brancos". O estojo peniano perdeu o sentido tradicional, não sendo, por isso, mais usado pelos homens desta sociedade.

Apesar do contato com a civilização, os homens e as mulheres Xavante mantêm um tipo de penteado nativo: cabelos lisos, de franjinha na testa e compridos sobre o ombro. Canevacci (2001), em seu contato com os Xavantes em 1984, observa que estes sinais da identidade étnica mantêm-se públicos, do pescoço para baixo, vencem os sinais de uma identidade em mutação - um "sincretismo corporal descontextualizado". Para o autor, esses modos híbridos e a forma pela qual essa mutação cultural se realiza, desenvolve uma forte tensão, descentrada e conflitual entre globalização e localização, entre processos de 
unificação cultural e pressões antropofágicas que descontextualizam, remastigam, regeneram.

Conhecido como um povo guerreiro, o Xavante sempre lutou para conservar seus costumes e tradições, cuja pintura corporal marca ainda hoje a participação do indivíduo em rituais e cerimônias. Regina Müller concluiu que "a arte corporal é um dos aspectos culturais que não perderam o lugar neste novo momento de sua história, confirmando sua importância enquanto elemento constitutivo de reprodução da sociedade". (MÜLLER, 1992: 142).

A pintura corporal Xavante é formada de pontilhados, quadrados, retângulos, traços e xadrezados nas cores vermelhas do urucum, negra do jenipapo e carvão, e, branca da argila. Os indivíduos são categorizados socialmente, segundo as relações que se estabelecem entre dois grupos de idade. Cada um dos grupos se caracteriza e se relaciona de acordo com cada um dos outros e com atributos que identificam o indivíduo como pertencente a uma categoria de idade. Desse modo, as diferentes pinturas são usadas pelos Xavantes de acordo com categorias de idade e função cerimonial em rituais de iniciação. Ao nível das categorias sociais, diz Regina Müller, "a ornamentação corporal sintetiza no corpo do indivíduo a representação simbólica da inter-relação dos sistemas classificatórios entre si”. (MÜLLER, 1979: 25).

Em julho de 2005, ocasião em que realizada a pesquisa de campo nas Aldeias Sangradouro e Abelhinha, tive oportunidade de assistir ao ritual atlético - Corrida do Noni, que assim como a furação de orelhas faz parte do ritual Danhõno. Durante quase um mês, os adolescentes e os atuais guerreiros competem 200 metros de corrida se preparando para a grande Tsa'uri'wa (corrida de $10 \mathrm{~km}$, onde geralmente os adolescentes desmaiam e são purificados dos espíritos negativos), finda a qual já serão considerados guerreiros, podendo, a partir de então, casar com as moças que já lhe estão prometidas.

Em Sangradouro, a corrida é realizada no centro da aldeia com a participação de aproximadamente 80 jovens da comunidade e também das aldeias vizinhas. Os espectadores se espalham ao redor do lugar, mantendo uma certa distância e torcendo por seus familiares. Os jovens ritéíwa, antes da corrida do Noni, se preparam recebendo na pele uma pintura específica para o evento - os retângulos vermelhos no estômago e nas costas. Nas pernas o preto do carvão, aglomerado com óleo de babaçu. Com o corpo pintado e "gravata no pescoço" os ritéi'wa consideram-se assim, preparados para a corrida. Ao término da corrida é realizada a Dança dos Padrinhos, que apresenta um passo bem marcado em movimento cíclico, enriquecida por um canto Xavante. Ao final do ritual, os componentes, para a realização desta dança, além do vestuário vermelho ou preto, revestem a pele com uma diversificada pintura corporal.

Berta Ribeiro, em relação à linguagem visual, expressa na ornamentação corporal indígena, conclui que "trata-se, como se vê, de um veículo de comunicação visual que alia ao prazer estético de adornar-se um mecanismo de socialização e valorização de símbolos étnicos expressos na pintura e nos ornamentos corporais. (RIBEIRO, 1989: 102)".

A idéia da ornamentação corporal, como "sistema de comunicação social rigidamente estruturado, que simboliza eventos, processos, categorias e status", combina elementos pictóricos e enfeites que produzem mensagens de conteúdo predominantemente social, revelando-a como "um dos elementos que contribuem para que a sociedade molde e construa a humanidade de cada um de seus membros, tornando-o "pessoa". (VIDAL, 1992: 286 e 287). 
A identidade cultural Xavante compreende um conjunto compartilhado de valores e percepções que se intercomunicam, formando uma rede contínua. É construída e se manifesta em tudo o que se pôde produzir no campo de sua cultura: os signos e símbolos transmitidos através das tradições, o artesanato, os rituais, a dança, a pintura corporal, as crenças e os mitos, os ritos de passagem, enfim, toda a produção de uma determinada sociedade que as diferencia das demais.

Usar o corpo decorado é uma maneira de apreender e expressar aspectos da realidade social, através da arte ou de um sistema de representação visual. O corpo constitui um suporte da memória xavante. Sua pele é um pergaminho que informa o modo de compreender e se relacionar com o universo.

Assim, os Xavantes mesmo com as influências causadas pelo contato com o homem branco, mantêm a herança deixada pelos antepassados de ornamentar seu corpo na participação de rituais, perpetuando as marcas internas de uma sociedade em transformação que informam e comunicam através da ornamentação corporal seu modo de estar no mundo.

Cabe, entretanto dizer, que este estudo não está de modo algum concluído, mas que significou a primeira inserção no mundo Xavante resultando numa experiência de aprender a captar a visão de "dentro" para assim compreender, além da natureza estética, a existência de expressões, de valores, de práticas diversas de uma sociedade que busca, nos tempos atuais, o reconhecimento de seu direito à diferença e de território.

\section{Referências Bibliográficas}

CANEVACCI, Massimo. Antropologia da Comunicação Visual. Rio de Janeiro: DP\&A Editores, 2001.

GEERTZ, Clifford. A interpretação das Culturas. Rio de Janeiro: LTC Editora, 1989.

MAYBURY-LEWIS, David. A Sociedade Xavante. Tradução Aracy Lopes da Silva. Rio de Janeiro: Livraria Francisco Alves Editora S/A, 1984.

MÜLLER, Regina A. P.. A linguagem colorida dos Xavante. Revista de Atualidade Indígena. Brasília, v. 3, n.16, p. 25-33, 1979.

A pintura do Corpo e os Ornamentos Xavante: Arte Visual e Comunicação Social. Dissertação de Mestrado. Campinas: UNICAMP, 1986. . "Mensagens visuais na ornamentação corporal Xavante". In:

RIBEIRO, Berta G. Arte Indígena, Linguagem Visual. Tradução Regina Regis Junqueira. São Paulo: Editora Itatiaia Limitada, 1989.

SILVA, Aracy Lopes. Nomes e Amigos: da prática Xavante a uma reflexão sobre os Jê. São Paulo: FFLCH/USP, 1986.

VIDAL, Lux. (Org.). Grafismo Indígena: Estudos de Antropologia Estética. São Paulo: Studio Nobel: Editora da Universidade de São Paulo: FAPESP, 1992. 